\title{
ESTRATÉGIAS DA LEITURA NA ESCOLA
}

Alba Regina Azevedo Arana, Gustavo Gasque Albano, Tamara da Silva Ferreira, Fernanda dos Santos Lorenti

Universidade do Oeste Paulista - UNOESTE. E-mail: alba@unoeste.br

\section{RESUMO}

Buscamos neste artigo, evidenciar a importância do papel da escola na formação do aluno e expor estratégias viáveis para se obter sucesso no desenvolvimento do educando como leitor. Por meio de referências bibliográficas, pudemos encontrar opiniões relevantes de autores que escreveram sobre o assunto, enriquecendo, assim, as ideias que inspiraram esse artigo. $O$ artigo que desenvolvemos apoiou-se na abordagem qualitativa que visa compreender cada implicação do processo de formação do leitor por meio de análises, interpretações e descrições subjetivas de cada situação. Ressaltamos que este artigo científico caracterizou-se como uma pesquisa Descritiva, que correlaciona fatos sem manipulá-los. Verificou-se que o aluno aprende a ler, lendo; porém, a primeira leitura que ele faz é a leitura de mundo, onde o mesmo está inserido, logo, é papel da escola proporcionar leituras de qualidade, por meio das quais o educando se sentindo confiante e amparado, o mesmo conseguirá obter uma leitura proveitosa e eficiente. Por meio da leitura o aluno terá capacidade de se enxergar inserido na sociedade, incentivado a participar dela com suas opiniões e a contribuir com suas ideias.

Palavras-chave: Aluno, Educação, Leitor, Professor, Sociedade.

\section{INTRODUÇÃO}

A leitura se faz presente na vida do indivíduo a partir do momento em que ele está apto a decifrar e compreender o mundo em que está inserido. No anseio de interpretar os acontecimentos ao seu redor e contextualizá-lo em sua vida, o indivíduo estará formando um tipo de leitura, mesmo inconscientemente.

Esta pesquisa tem como objetivo esclarecer o papel da escola na formação do leitor e propor estratégias para leitura significativa no ambiente escolar.

Segundo Freire (2008, p. 11), "A leitura do mundo precede a leitura da palavra, daí que a posterior leitura desta não possa prescindir da continuidade da leitura daquele. Linguagem e realidade se prendem dinamicamente". Freire sintetiza que a leitura gráfica, ou seja, dos livros, revistas, jornais é precedida pela leitura da vida. Cada ser humano tem vivências e experiências diferenciadas, portanto, cada um tem uma forma de interpretar uma determinada situação, conforme os padrões da construção de ideias presentes na realidade na qual se encontra inseridos. 
Assim, o objetivo da escola é o de dar a continuidade ao desenvolvimento da leitura. Ela tem o papel de formar um cidadão crítico, envolvido com as causas sociais, ciente do mundo ao seu redor.

\section{MÉTODOS}

A coleta de dados foi obtida por meio de levantamentos bibliográficos, em livros, artigos, sites científicos relativos ao tema em questão. Segundo Andrade (2001, p.121) “Pesquisa é o conjunto de procedimentos sistemáticos, baseados no raciocínio lógico, que tem por objetivo encontrar soluções para problemas propostos, mediante a utilização de métodos científicos".

De acordo com Ruiz (1976, p.58) “a pesquisa bibliográfica consiste no exame desse manancial, para levantamento e análise do que já se produziu sobre determinado assunto que assumimos como tema da pesquisa".

A abordagem qualitativa é a base para a realização desse trabalho, configurando-se como um estudo bibliográfico, para recuperar as informações a respeito do que já foi publicado sobre o tema. Esse caminho metodológico permite entrar em contato direto com fontes científicas sem, necessariamente, precisar recorrer aos fatos da realidade empírica.

Minayo (1999, p.54-55) diz que: “a abordagem qualitativa não pode pretender o alcance da verdade com o que é certo ou errado; deve ter como preocupação primeira a compreensão da lógica que permeia a prática que se dá na realidade”.

Assim, a escolha pela pesquisa qualitativa, do tipo bibliográfica, deve-se ao fato de que ela possibilita a compreensão, do fenômeno estudado, uma vez que considera a dinâmica interna da escola e ainda que há uma interação entre o mundo real e o sujeito. Permite ainda aprofundar a reflexão sobre os diversos aspectos da realidade.

Trata-se de um estudo de caráter exploratório e descritivo e os dados coletados serão apresentados e analisados a partir da abordagem qualitativa e terão a interpretação como meta.

\section{RESULTADOS}

A leitura tem um papel fundamental na formação do cidadão crítico e comprometido com o seu desenvolvimento humano. Para tanto, a escola deverá dispor de uma estrutura de qualidade; livros atuais e em bom estado de uso, usufruir de uma infraestrutura sólida, com ambientes bem projetados e bibliotecas conservadas. Conforme Freire $(2008$, p. 22): “A compreensão crítica da alfabetização, que envolve a compreensão igualmente crítica da leitura, 
demanda a compreensão crítica da biblioteca". Assim, quando a escola investe na biblioteca, tanto na parte física, disponibilizando um ambiente confortável onde o aluno se sinta bem e incentivado a ler um livro tranquilamente, quanto na parte motivacional, exercendo e empregando a cultura da leitura com professores que incentivem à ida à biblioteca. A escola, assim, exercerá seus deveres quanto ao seu papel de promover a cultura da leitura e assim formar cidadãos capazes de compreender melhor o contexto em que estão inseridos e de lidar com questões sociais, emocionais, afetivas e psicológicas. De acordo com os Parâmetros Curriculares Nacionais (BRASIL, 1998, p.36):

Não se formam bons leitores oferecendo materiais empobrecidos, justamente no momento em que as crianças são iniciadas no mundo da escrita. As pessoas aprendem a gostar de ler quando, de alguma forma a qualidade de suas vidas melhora com a leitura. No âmbito desta abordagem, fica evidente que os recursos didáticos e procedimentos devem viabilizar e enriquecer a forma como se procede a uma atividade, seja ela individual ou coletiva, com intuito de facilitar à criança desenvolver seus próprios esquemas mentais na organização do processo de aprendizagem. Sabe-se que os procedimentos estão relacionados ao domínio do uso de instrumentos de trabalho, que possibilitem a construção de conhecimento e o desenvolvimento de habilidades. Favorecem, portanto, a construção, por parte dos alunos, de instrumentos que os ajudarão a analisar os resultados de sua aprendizagem e os caminhos percorridos para efetivá-la. Como exemplo, tem-se a realização de pesquisas, produções textuais, resolução de problemas, elaboração de sínteses e outros.

Em boa parte dos casos o indivíduo não recebe apoio ou incentivo em casa para desenvolver o hábito da leitura. Muitas vezes pela situação financeira da família não ser adequadamente suficiente para manter tal costume, outras vezes pelo círculo vicioso que passa de pai para filho, pois onde os pais não lêem os filhos provavelmente não lerão também. Daí entra a escola, suprindo, complementando essa brecha.

Muitos alunos talvez não tenham muitas oportunidades fora da escola, de familiarizar-se com a leitura; talvez não vejam muitos adultos lendo; talvez ninguém lhes leia livros com freqüência. A escola não pode compensar as injustiças e as desigualdades sociais que nos assolam, mas pode fazer muito para evitar que sejam acirradas em seu interior. Ajudar os alunos a ler, a fazer com que se interessem pela leitura, é dotá-los de um instrumento de aculturação e de tomada de consciência cuja funcionalidade escapa dos limites da instituição. (SOLÉ, 1998, p. 51) 
Além de alfabetizar, ensinando o aluno a formar sílabas, palavras e frases, a escola mediada pelo educador enfrenta o desafio de fazê-lo entender o significado do enunciado ali utilizado, estimulá-lo a formar opiniões sobre o conteúdo lido, além de, e o mais importante, fazêlos raciocinar. O professor empenhado em transmitir a mensagem inclusa no objeto de leitura, deve estar atento aos benefícios que isso trará para seus alunos, avaliando se será viável e se está de acordo com as condições de cognição dos mesmos. O objetivo central da utilização da leitura é fornecer a visão de mundo para o educando, inseri-lo na sociedade por meio da leitura. De acordo com os Parâmetros Curriculares Nacionais (BRASIL, 1998, p.149):

O envolvimento do aluno no processo de aprendizagem deve propiciar ao aluno encontrar sentido e funcionalidade naquilo que constitui o foco dos estudos em cada situação de sala de aula. De igual maneira, propiciar a observação e a interpretação dos aspectos da natureza, sociais e humanas, instigando a curiosidade para compreender as relações entre os fatores que podem intervir nos fenômenos e no desenvolvimento humano.

As formas de ensinar e aprender são contextualizados e dessa forma permite ao aluno se relacionar com os aspectos presentes da vida pessoal, social e cultural, mobilizando as competências cognitivas e emocionais já adquiridas para novas possibilidades de reconstrução do conhecimento.

Isso evidencia a necessidade de trabalhar com o desenvolvimento de competências e habilidades, às quais se desenvolvem por meio de ações e de vários níveis de reflexão que congregam conceitos e estratégias, incluindo dinâmicas de trabalho que privilegiam a resolução de problemas emergentes no contexto ou no desenvolvimento de projetos.

O papel da escola, mais do que formar leitores, é também o de formar leitores que contextualizem o objeto lido com a sua carga de conhecimento, Leitores que raciocinam, que leiam e entendam não a grafia apenas, mas que mantenham uma relação crítica e de opiniões com o texto lido, que buscam entender o que foi transmitido com o objeto de leitura. Ainda indicam, os Parâmetros Curriculares Nacionais (BRASIL, 1999, p. 69):

[...] formar um leitor competente, supõe formar alguém que compreenda o que lê; que possa aprender a ler também o que não está escrito, identificando elementos implícitos; que estabeleça relações entre o texto que lê e outros textos já lidos; que saiba que vários sentidos podem ser atribuídos a um texto [...]

Para se conseguir conquistar o gosto dos alunos à leitura, é necessário o uso de algumas estratégias, para que todos, desde os que têm facilidade de cognição até os que têm 
dificuldade, consigam chegar a um nível satisfatório de compreensão e aproveitamento, cada um dentro do seu limite. O objetivo é sempre conquistar o aluno e fazê-lo interagir com o conteúdo passado, formar opiniões e ensiná-lo a expressá-las.

Devemos compreender estratégias aqui como um procedimento de cunho elevado que abrange a presença de objetivo a ser alcançado, o planejamento de ações desenvolvidas no intuito de atingi-lo, bem como sua avaliação.

Como disse Coll (apud SOLÉ, 1998, p. 68): “Procedimento, com frequência chamado também de regra, técnica, método, destreza ou habilidade, é um conjunto de ações ordenadas e finalizadas dirigidas à consecução de uma meta".

Essas estratégias de leitura são usadas para se pôr em prática os mecanismos de ações mentais desenvolvidas pelo leitor para se construir um sentido, que o leve a compreender com maior aproveitamento o texto lido.

Consideramos as estratégias de compreensão leitora como um tipo particular de procedimento de ordem elevada. Como poderão verificar, cumprem todos os requisitos: tendem à obtenção de uma meta, permitem avançar o custo da ação de leitor, embora não a preservem totalmente; caracterizam-se por não estarem sujeitas de forma exclusiva a um tipo de conteúdo ou a um tipo de texto. (SOLÉ, 1998, p. 72).

Pode se iniciar com uma estratégia essencial, a da interação entre professor e aluno, formando a relação por meio do ensino. O aluno se depara com o desafio de compreender o conteúdo da matéria ali imposta, e o professor é o encarregado de lhe auxiliar e orientar.

A leitura é uma estratégia de interação entre o educador e o aluno. Por meio dela é estabelecida uma comunicação e uma troca de ideias, de diferentes interpretações do objeto de leitura.

A leitura desenvolvida em sala de aula é apresentada por Solé (1998) em três etapas de atividades com o texto: o antes, o durante e o depois da leitura.

Em sua opinião, as crianças que crescem desenvolvendo a dificuldade da leitura poderiam ter condições de atingir níveis satisfatórios da mesma se fossem previamente orientadas a ler do modo apropriado.

Seguindo os passos sobre as estratégias de compreensão leitora propostas por Solé (1998), temos:

a) Atividades antes da leitura:

i) Levantamento do conhecimento prévio sobre o assunto; 
ii) Antecipação do tema ou ideia principal como: título, subtítulo, do exame de imagens.

iii) Expectativas em função do autor ou instituição responsável pela publicação.

b) Atividades durante a leitura:

i) Retificação, confirmação ou rejeição das idéias antecipadas ou expectativas criadas antes do ato de ler;

ii) Utilização do dicionário para consulta, esclarecendo sobre possíveis dúvidas do vocabulário;

iii) Identificação de palavras-chave;

iv) Suposições sobre as conclusões implícitas no texto, com base em outras leituras, valores, experiências de vida, crenças;

v) Construção do sentido global do texto;

vi) Busca de informações complementares;

vii) Relação de novas informações ao conhecimento prévio;

viii) Identificação referencial a outros textos.

c) Atividades para depois da leitura:

i) Construção do sentido sobre o texto lido;

ii) Troca de opiniões e impressões a respeito do texto;

iii) Relacionar informações para concluir ideias;

iv) Avaliar as informações ou opiniões expressas no texto lido;

v) Avaliar criticamente o texto abordado.

Para seguir essas ideias apresentadas pela autora, o leitor deve dominar os níveis mais básicos da leitura, com mediação de um professor a lhe orientar como proceder ao longo do processo da leitura.

Um tipo de leitura estratégica que busca agregar conhecimentos, facilitando os passos do descobrimento das informações, é a leitura informativa ou leitura de estudos. Esse tipo de leitura é estrategicamente utilizado nas escolas, e busca auxiliar na construção de trabalhos e projetos ou para responder questões específicas. Portanto, é de extrema importância utilizar as fases da leitura informativa ou de estudo para se obter uma leitura proveitosa. De acordo com Cervo \& Bervian (apud ANDRADE, 1999, p. 20-21) essas fases são:

I) leitura de reconhecimento ou pré-leitura: também classificada por outros autores como leitura prévia ou de contato, tem como finalidade dar uma visão global do assunto, ao mesmo tempo em que permite ao leitor verificar a existência ou não de informações úteis para 
o seu objetivo específico; trata-se de uma leitura rápida, "por alto", apenas para permitir um primeiro contato com o texto;

II) leitura seletiva: o objetivo é a seleção de informações mais importantes e que interessam à elaboração do trabalho em perspectiva;

III) leitura crítica ou reflexiva: leitura de análise e avaliação das informações e das intenções do autor. A reflexão se dá por meio da análise, comparação e julgamento das ideias contidas no texto;

IV) leitura interpretativa: é a mais completa, é o estudo aprofundado das ideias principais, onde se procura saber o que realmente o autor afirma, quais os dados e informações ele oferece, além de correlacionar as afirmações do autor com os problemas em questão.

Depois de feita essa análise e o julgamento sobre o que foi lido, o leitor terá autonomia para interpretar e debater sobre o objeto lido, agregando aos seus conhecimentos novas informações e opiniões. Sob o olhar do professor, os alunos devem ser guiados a maneira correta de como se analisar esse tipo de texto, e formar opiniões sobre o conteúdo da leitura..

\section{DISCUSSÃO}

Observou-se que as estratégias de leitura são válidas, porque por meio delas pode se alcançar um melhor desenvolvimento da capacidade leitora do aluno, levando-o a tomar opinião e partido sobre o objeto lido. Tais estratégias de leitura permitem delimitar o espaço do ensino, restringindo cada estratégia para níveis diferentes de escolaridade, auxiliando na compreensão dos textos lidos, e assim, incentivando os alunos a fazer da leitura um hábito.

Trabalhar com estratégias de leitura permite ao leitor ampliar e modificar os processos mentais de conhecimento, bem como compreender um texto. Compreender é a base para que todas as crianças se engajem completamente na leitura de livros de literatura e se tornem leitoras (GIROTTO; SOUZA, 2010, p.108).

Assim, o educador terá uma meta, um horizonte por onde se guiar, podendo explorar o que o educando tem de melhor. Com uma boa estratégia de leitura pode se observar que o rendimento do aluno é positivo, pois ele passa a entender melhor a leitura e os meios de aprender. A partir do momento que a criança é inserida no universo da leitura, a sua vida passa a ter mais sentido, pois a literatura proporciona o entendimento das ciências, e faz com que o indivíduo crie o hábito de refletir, proporcionando assim uma evolução interior, evolução do pensar e do viver. 
Nenhum lugar seria melhor para ser ministrada a prática da leitura do que no ambiente escolar, onde a criança e o adolescente têm todo um aparato, uma estrutura para se ter sucesso na sua aprendizagem. Nesse ambiente é que se encontram profissionais habilitados para ministrar aulas; os professores que acompanham a vida escolar do educando desde a sua préescola, são os verdadeiros responsáveis pelo sucesso do ensino da leitura. Um professor apaixonado pelo que faz é sinônimo de alunos apaixonados pelo que aprendem. As estratégias de ensino funcionam, desde que existam professores que acreditem nelas e na capacidade de que com paixão e vontade o sucesso vem. Talvez essa seja a maior estratégia de ensino da leitura, a paixão de ensinar.

Aprender a ler não é muito diferente de aprender outros procedimentos ou conceitos. Exige que a criança possa dar sentido àquilo que se pede que ela faça, que disponha de instrumentos cognitivos para fazê-lo e que tenha ao seu alcance a ajuda insubstituível do seu professor, que pode transformar em um desafio apaixonante o que para muitos é um caminho duro e cheio de obstáculos. (SOLÉ, 1998, p. 65)

Portanto, cabe a escola, sob o domínio do professor, proporcionar esse momento ao aluno, de se sentir inserido no mundo. O hábito saudável da leitura propiciará isso, desde que o educador não imponha regras severas à leitura, como punições ou ações forçadas. Deve-se respeitar as limitações de cada aluno, inseri-lo no mundo da leitura, debatendo, dando-lhe voz e oportunidade de expressar um pouco de seu mundo, para que ele se sinta incluso no mundo da leitura, assim, se familiarizando e se sentindo mais a vontade e confortável diante dos desafios que a leitura impõe.

Então, a leitura na escola é fundamental para a formação do aluno leitor. A escola tem o papel de suprir a brecha que a sociedade e a família não atendem, buscando formas de fazer com que o aluno reflita sobre o mundo ao seu redor, interprete a vida em sociedade, além de dar oportunidade para que ele se supere e desenvolva a competência e a autocrítica. Por conseguinte, o ambiente escolar é o ideal para o ensino desta prática. Para tanto, deve ser rico em recursos didáticos e em profissionais capacitados que saibam ministrar as estratégias necessárias para que haja excelência no ensino da leitura.

\section{REFERÊNCIAS}

ANDRADE, Maria Margarida de. Introdução à metodologia do trabalho científico: elaboração de trabalhos na graduação. 5. ed. São Paulo: Atlas, 2001. 
ANDRADE, Maria Margarida de. Introdução à metodologia do trabalho científico. 4. ed. São Paulo: Atlas, 1999.

BRASIL. Ministério da Educação. Secretaria de Educação Fundamental. Parâmetros Curriculares Nacionais: Língua Portuguesa. Brasília/ DF: MEC, SEF, 1998.

BRASIL. Ministério da Educação. Parâmetros Curriculares Nacionais: língua portuguesa. Brasília: SEED, 1999.

FREIRE, Paulo. A importância do ato de ler: três artigos que se completam. 49 ed., São Paulo: Cortez, 2008.

GIROTTO, C. G. G.S.; SOUZA, R. J. Estratégias de leitura: para ensinar alunos a compreender o que leem. In: SOUZA, Renata Junqueira (org) . Ler e compreender: estratégias de leitura. Campinas, SP: Mercado de Letras, 2010.

MINAYO,M.C.S. (Org) Pesquisa Social: Teoria Método e Criatividade. 13.ed. Petrópolis - RJ: Vozes, 1999

RUIZ, João Álvaro. Metodologia Científica - Guia para Eficiência nos estudos. São Paulo: Atlas, 1976.

SOLÉ, Isabel. Estratégias de Leitura; trad. Cláudia Schilling. 6 ed. Porto Alegre: ARTMED, 1998. 